\title{
Jornalismo científico aplicado à área de energia no contexto do desenvolvimento sustentável
}

\author{
Vânia Mattozo \\ Jornalista, mestre na área de mídia e conhecimento, assessora de \\ imprensa do Instituto de Engenharia Biomédica, UFSC. \\ E-mail:vania@ieb.ufsc.br

\section{Cornélio Celso de Brasil Camargo} \\ Engenheiro eletricista, doutor na área de conservação de energia, \\ professor adjunto do Departamento de Engenharia Elétrica, UFSC. \\ E-mail: celso@labplan.ufsc.br
}

Nilson Lemos Lage

Jornalista, doutor em lingüística, professor titular do Departamento de Jornalismo, UFSC.

E-mail: lage@floripa.com.br

\section{Resumo}

Este artigo trata de uma pesquisa aplicada de jornalismo científico on-line que fundamenta a questão energética contemplada no contexto do desenvolvimento sustentável. A pesquisa, desenvolvida em nível de mestrado, originou uma mídia digital on-line com informações científicas e tecnológicas que permitem visualizar não somente o âmbito técnico, mas também a efetiva relação interdisciplinar do tema com outras áreas de conhecimento, o que constitui um fato de particular importância no contexto de abordagem do desenvolvimento sustentável.

\section{Palavras-chave}

Jornalismo científico; Jornalismo on-line; Energia; Desenvolvimento sustentável; Ambiente.

\section{Scientific journalism applied to the area of electrical power in the context of a sustainable development}

\section{Abstract}

This paper treats of a research applied to on-line scientific journalism which is the basis for the electrical power issue in the context of the sustainable development. The research was developed on a Master Degree level, which gave origin to an online digital media with scientific information and technologies which allow a visualization of not only the technical range, but also the effective interdiscipline relation with reference to other areas of knowledge. This is very important for an approach of the sustainable development.

\section{Keywords}

Scientific journalism; On-line journalism; Power area; Sustained development; Environment.

\section{INTRODUÇÃO}

O mais trivial que se pode dizer sobre energia é que o termo abarca múltiplos aspectos, desde a explicação científica fornecida pela física até o significado dado pela percepção comum. A utilização do conceito é diversa e, freqüentemente, equivocada, considerando as circunstâncias em que o termo é empregado ou pensado, algumas vezes com sentidos vagos e, vez por outra, até esotéricos. Corrêa ${ }^{1}$ constata a gravidade desse distanciamento gerado na vida cotidiana para a maioria das pessoas: “(...) não seria tão grave se o objetivo desse significante - a coisa que a palavra exprime - não estivesse relacionado com a nossa qualidade de vida, mais ainda, e principalmente, com a nossa comida - ingrediente material básico da existência - e conseqüentemente com a sua negação, a morte" (1987, p. 6).

Criar condições adequadas de vida é a intenção básica de toda ação humana na busca do desenvolvimento. Contudo, a qualidade de vida requer um equilíbrio dinâmico entre as dimensões ecológicas, sociais e econômicas visando a garantir a própria sustentabilidade e da qual um dos fundamentos diz respeito à energia, sua disponibilidade, seus usos e seus efeitos sobre o ambiente.

A mídia, como instrumento de acesso às informações que circulam em espaços normalmente restritos, tem uma grande e ainda crescente importância no esclarecimento público sobre a questão da energia e suas implicações sociais, ambientais e econômicas, fornecendo subsídios para que o cidadão comum conheça os fatos e as perspectivas que cercam as suas condições de vida.

\section{OBJETIVOS}

Considerando que o tema da pesquisa aplicada, a energia, possui duas implicações primárias para a vida prática, como elemento fundamental para a qualidade de vida e como insumo básico para as atividades produtivas e econômicas, o projeto procurou abarcar as principais relações existentes entre o setor energético e outras áreas de atividades e conhecimentos (economia e ambiente), contextualizando a questão energética no âmbito do desenvolvimento sustentável. 
O objetivo final da pesquisa foi desenvolver uma mídia - interativa e on-line - sobre energia que contemplasse essa relação interdisciplinar, reunindo informações elementares e especializadas, com destaque para o conhecimento científico e tecnológico gerado nessas áreas de domínio. Também se objetivou agregar apoio às iniciativas empreendidas pela Universidade Federal de Santa Catarina para promover o uso racional de energia e desenvolver um plano de gestão ambiental dentro do campus universitário.

A Agenda 21, que trata de um plano de ações baseadas na tese do desenvolvimento sustentável, dedica um capítulo exclusivamente ao papel da informação, estabelecendo os diversos escopos e conteúdos informativos (científico, técnico-econômico, sociopolítico e geopolítico) destinados a obter níveis de sustentabilidade nos processos sociais ${ }^{2}$.

Em primeira instância, essa perspectiva remete à influência dos meios de comunicação para promover as prerrogativas reunidas na Declaração Universal dos Direitos Humanos, como os direitos de tomar parte na direção dos negócios públicos (artigo 21) e de participar do progresso científico e dos benefícios resultantes (artigo $27)^{3}$. De outra forma, assumindo que o domínio da informação está ligado ao poder de interferir e reorientar as ações humanas, vários autores salientam a importância da mídia como elemento mediador no contato com os problemas ambientais e na discussão sobre os modelos de desenvolvimento adotados ${ }^{4,5,6}$.

Em grande medida, a busca de sustentabilidade depende do conhecimento gerado pela investigação científica, razão pela qual vários autores pontuam a necessidade de esclarecimento público e o estímulo à participação e mobilização social como os principais compromissos políticos e culturais do jornalismo dedicado à ciência, tecnologia e ambiente ${ }^{7,8,9}$. Assim, cabe aos profissionais dessas especialidades disseminar novos valores, novas tendências empresariais e inovações tecnológicas, preferencialmente sobre métodos mais eficientes e racionais para uso dos recursos naturais.

\section{REFERENCIAL TEÓRICO}

A busca por fontes de energia sempre permeia todos os processos de evolução humana, como forma de atender às exigências básicas de suprimento e ainda garantir melhores condições de vida. Contudo, não existe determinismo na produção energética. Dependendo do uso e da evolução da tecnologia, quase todos os sistemas energéticos possuem flexibilidade de utilização e comportam potencial de melhoria e rendimento. Essa capacidade de adaptação produz uma inércia que tem, entre todas as forças produtivas, a vida mais longa. Sem dúvida, a própria energia humana, sempre presente, torna-se um elemento primordial tanto para promover a durabilidade desses sistemas quanto para gerar algumas das principais transformações da biosfera e da estrutura social $^{10}$.

A questão energética passou a ocupar lugar de destaque no plano internacional a partir de 1950, quando o consumo crescente dos recursos naturais disponíveis e os indícios de sérios agravos ao ambiente decorrentes do processo intensivo de industrialização começaram a mobilizar estudiosos e pesquisadores para o debate sobre os estilos de desenvolvimento adotados ${ }^{11,12}$. Nas décadas seguintes, crises econômicas e políticas, assim como novos acidentes ambientais, fortaleceram crescentemente a discussão em torno de critérios sustentáveis para planejar o desenvolvimento das nações, visando a reunir condições adequadas para sustentar a vida presente, sem comprometer o mesmo direito às gerações futuras.

No entanto, um fato de singular importância surgiria na contramão desses debates. A reintrodução da filosofia de livre comércio e liberalização do mercado, a partir de 1980, provocou um processo abrangente de reformas, modificando a atuação do Estado na economia. Como conseqüência, a área de energia englobada nesse processo tem sofrido alterações na sua forma de organização e nos seus mecanismos de regulação e controle. O Brasil está imerso atualmente em um modelo de desenvolvimento energético comum a toda a América Latina, baseado na integração regional, na extensão do uso de gás natural e na inserção de companhias privadas em todas as áreas de energia ${ }^{13}$. Essas novas diretrizes, no entanto, não expressam uma solução eficiente para os problemas energéticos dos países em desenvolvimento, haja vista que muitas causas desses problemas estão ligadas à própria natureza do desenvolvimento, estabelecida pelo alto nível de dependência do exterior, à desarticulação entre os setores internos, à inadequação às necessidades básicas e a sérios danos ao ambiente. Similarmente, estas são as mesmas características típicas do subdesenvolvimento ${ }^{14}$.

Em vários países menos avançados, a relação de dependência com o exterior é particularmente visível no setor energético, amplamente dominado por empresas estrangeiras. Do mesmo modo, muitos padrões externos servem como parâmetros para determinar as opções tecnológicas, o dimensionamento de projetos e as escolhas dos modos de produção e uso da energia, sem considerar as condições internas de suprimento e as 
necessidades reais de abastecimento. A adoção de modelos externos destoa da realidade em que vive boa parte da população, sem renda para adquirir os bens de consumo disponíveis, e privilegia ações públicas inadequadas a condições e necessidades internas. Em geral, esses modelos conduzem a níveis consideráveis de desperdício entre os consumidores com maior renda, enquanto uma parcela significativa da população permanece muito aquém da satisfação das exigências básicas.

\section{METODOLOGIA}

A implementação da mídia digital contém um referencial teórico aprofundado na relação da questão energética com as áreas econômica, política e ambiental, englobando os aspectos pertinentes à abordagem sistêmica do tema energia segundo os critérios de sustentabilidade. O trabalho iniciou com a leitura bibliográfica do material referente às áreas de energia, desenvolvimento sustentável e ambiente, para levantar os tópicos mais relevantes a serem considerados. As ferramentas de busca existentes na Internet permitiram reunir as informações mais atualizadas, oriundas de bancos de dados e portais especializados. Da mesma forma, os recursos da internet (portais e endereços eletrônicos) foram usados para interagir com pesquisadores e outros jornalistas. O levantamento de opinião sobre o noticiário de energia e ambiente com profissionais da área de jornalismo científico e ambiental, utilizado como ferramenta de auxílio ao desenvolvimento do projeto, tornou-se viável com a localização desses jornalistas por meio das listas eletrônicas de discussão, facilitando o acesso e o envio dos respectivos formulários de consulta. A mídia implementada empregou as metodologias mais conhecidas para construção de ambientes informativos on-line (sites), conjugando simultaneamente os aspectos de comunicação interativa e prática jornalística em redes de computadores.

\section{DESENVOLVIMENTO DA PESQUISA}

Antes da implementação da mídia, foi realizada uma pesquisa de opinião entre jornalistas profissionais ligados à área ambiental e estudantes de jornalismo em fase de conclusão de curso. O questionário, distribuído aos profissionais pela internet e aos alunos diretamente em sala de aula, baseou-se em critérios qualitativos utilizados por Medina ${ }^{15}$, com respostas abertas e/ou estimuladas. Dezenove profissionais da Rede Ambiental de Jornalistas e do Grupo Intercom - Núcleo de Pesquisa em Comunicação Científica e Ambiental - residentes no Distrito Federal e nos estados do Piauí, Rio de Janeiro,
São Paulo, Rio Grande do Sul, Bahia, Santa Catarina e Mato Grosso, e também no exterior, (Portugal) responderam ao questionário. Os 24 estudantes que participaram da pesquisa foram alunos do Curso de Jornalismo da Universidade do Sul de Santa Catarina (Unisul - unidade Tubarão), com formatura prevista para dezembro de 2001.

Uma das perguntas principais tratou da análise da cobertura realizada pela imprensa sobre energia e ambiente. Entre os estudantes, a avaliação da maioria foi razoável (54,17\%) e boa (29,17\%). Entre os jornalistas, a maior parte com mais de dez anos de profissão, a cobertura foi avaliada como pouco contextualizada $(47,06 \%)$ e distorcida ou contraditória $(41,18 \%)$. Aos profissionais que já trabalharam com pautas sobre esses assuntos (nove jornalistas) perguntou-se sobre as dificuldades para fazer as matérias. Mais da metade $(66,7 \%)$ respondeu que o pouco tempo para produzir a matéria é a maior dificuldade encontrada. Em segundo lugar, foram citados os problemas com fontes e informações (33,3\%). As maiores dificuldades apontadas com as fontes é que elas não gostam de falar com jornalistas $(22,2 \%)$, ou que é difícil encontrar fontes especializadas $(11,1 \%)$ para esses assuntos. Nas dificuldades relativas à informação, os jornalistas responderam que existe muita informação sobre esses temas $(11,1 \%)$, ou que as informações são contraditórias $(11,1 \%)$. Com o mesmo índice de resposta também foram citados problemas com dados de arquivo e com a divulgação de material fora da grande imprensa. A maioria desses profissionais $(87,5 \%)$ acompanha os assuntos de energia e ambiente pelas revistas e internet brasileiras.

Os dados obtidos auxiliaram na escolha dos conteúdos que contemplassem uma tentativa de solução do problema principal apontado (contextualização). Dessa forma, os temas abrangidos - energia, ambiente e desenvolvimento - foram reunidos em seções com informações básicas, informações especializadas e informações de suplementares.

\section{Escolha da mídia}

Em virtude de configurar um sistema interativo, aberto e descentralizado de consulta e disponibilidade de informações estruturadas na forma de hipertextos, a Web (World Wide Web) é o segmento da rede mundial de computadores (internet) que apresentou crescimento maior na última década. 
Dentre suas principais características, pode-se destacar a disponibilidade universal de informação, a flexibilidade para atender a todas as plataformas de informática (hardware e software), o baixo custo relativo à reprodução e distribuição dos conteúdos e a possibilidade de incluir múltiplas formas de apresentação da mensagem (texto, imagem, áudio e vídeo). O formato de hipertexto virtual também facilita a indexação eletrônica e a atualização dos dados, reduzindo as restrições de tempo e espaço físico. Para o usuário, os principais benefícios são o acesso instantâneo e global, com baixo custo, a uma informação com conteúdo mais rico do que o existente em outros meios e que pode ser reusada (copiada, transmitida, impressa).

Pelo teor de suas características, na visão de Correa ${ }^{16}$, esse novo meio de comunicação pode converter-se em um agente de transformação social verdadeiramente revolucionário. Uma revolução que não se atém ao caráter tecnológico expresso pelos seus princípios de uso prático (reuso e recuperação da mensagem virtual e interativa), abrangendo também a potencialidade de formar a base global para uma nova sociedade inscrita em um entorno em que desaparecem as barreiras de tempo e espaço, cuja maior qualidade reside na expressão e compartilhamento das diferenças individuais, sem interferência de agentes que determinem o que se deve dizer ou ouvir.

Conforme Colle ${ }^{17}$, a forma hipertextual para transmissão de conhecimentos corresponde efetivamente ao que ocorre com a informação jornalística, tendo em vista os contextos de funcionalidade:

a) um corpo amplo de informação é organizado em numerosos fragmentos;

b) os fragmentos mantêm relação entre si;

c) os usuários necessitam de uma pequena fração do conteúdo de cada vez.

Some-se a isto o fato de ser uma aplicação baseada em computador, permitindo a exploração de recursos interativos que não estão disponíveis em outros meios.

Dessa forma, Colle nomeia como sistema documental jornalístico todo sistema estruturado na forma de espaço de informação multidimensional, composto necessariamente por um conjunto de dados relacionados que permitem diversas formas de leitura e combinação. Preliminarmente, esses dados devem ser definidos e organizados de acordo com a natureza dos referentes que representam e de seus atributos e, depois, mantidos mediante sistemas informáticos que suportem a conservação maciça e flexível.
No âmbito da prática e da qualificação em jornalismo sobre ciência e tecnologia, algumas pesquisas e experiências evidenciam a contribuição aportada pelo ambiente interativo on-line, tendo em conta a aplicação de princípios fundamentais como a intertextualidade, a inclusão de material de referência e uma estrutura de navegação adequada para transitar entre os contextos de informação. Além disso, a interatividade digital promove maior participação do usuário tanto na seleção e na crítica dos conteúdos, quanto no acesso às fontes das quais se servem os próprios produtores da informação ${ }^{18,19,20}$.

\section{Estrutura da mídia digital}

Nielsen $^{21,22,23}$ estabeleceu os critérios que são os mais amplamente adotados, em termos de usabilidade e de linguagem, na construção de sites. Dois critérios fundamentais, nesse sentido, dizem respeito à facilidade no uso e à utilidade das informações publicadas. Dessa forma, o projeto da mídia considerou que os níveis de conteúdo deveriam priorizar informações de interesse geral e temas específicos dentro dos assuntos abordados, além de proporcionar informações claras, objetivas e pouco extensas. De acordo com os critérios adotados para o desenvolvimento da mídia, resolveu-se:

a) priorizar o conteúdo;

b) inserir componentes com tempo reduzido para carregamento na tela ou para armazenagem local no computador do usuário;

c) construir um ambiente relevante às necessidades do usuário, compatível com a maioria dos navegadores (browsers) utilizados;

d) utilizar links e hiperlinks padronizados para ampliar o acesso à informação;

e) utilizar títulos (para links e páginas) claros, simples, diretos e informativos;

f) contextualizar as páginas por meio de chamadas de navegação;

g) padronizar a aparência e a funcionalidade dos mecanismos de navegação, orientando o usuário na busca do conteúdo;

h) fornecer fontes e/ou autores das informações disponibilizadas;

i) colocar à disposição mecanismos de interação com a produtora do site. 
O conteúdo da mídia, denominado Caderno Digital de Informação sobre Energia, Ambiente $\mathcal{E}$ Desenvolvimento, foi selecionado recorrendo a níveis de informação, a saber:

\section{Nível básico}

Refere-se ao nível introdutório, visando a fornecer informação elementar sobre os temas abordados (seções Energia, Ambiente, Desenvolvimento). Nesse sentido, foram selecionados os tópicos potencialmente mais relevantes de cada tema (dados, conceitos, estado-da-arte etc.);

\section{Nível especializado}

Trata-se de um nível de informação mais detalhado. No caso, reporta-se diretamente ao gênero jornalístico que contextualiza uma série de assuntos pertinentes a cada tema (seção Entrevistas).

\section{Nível complementar}

Reúne informações adicionais de caráter complementar. No caso (seção Trivia), agrupa dados específicos de uso prático (tabelas, guias de segurança e economia, manuais, cartilhas), além de conteúdos de entretenimento (testes, jogos etc.).

Essa arquitetura da informação foi organizada segundo o modelo de árvore (figura 1), em vista da facilidade no uso e na manutenção dos conteúdos, tomando o menu principal da página de entrada como tronco. Internamente, utilizou-se a estrutura vinculada para disponibilizar acesso às informações existentes em outras páginas.

Normalmente, a página de entrada (ou homepage) é o ponto inicial pelo qual muitos visitantes começam a explorar um site. Torná-la sucinta e objetiva, com informação significativa e atualizada, melhora a atratividade para o público visitante. Dessa forma, o conteúdo da página de entrada (figura 2) procurou orientar os usuários sobre os objetivos do site, disponibilizando de imediato a navegação para alguns conteúdos (ao centro e abaixo). Também foi programada a entrada automática e aleatória dessa página, destacando os conteúdos dinâmicos da seção Entrevistas, além de alguns conteúdos internos associados (lado direito da tela).

\section{FIGURA 1}

Exemplo de arquitetura de informação modelo de árvore

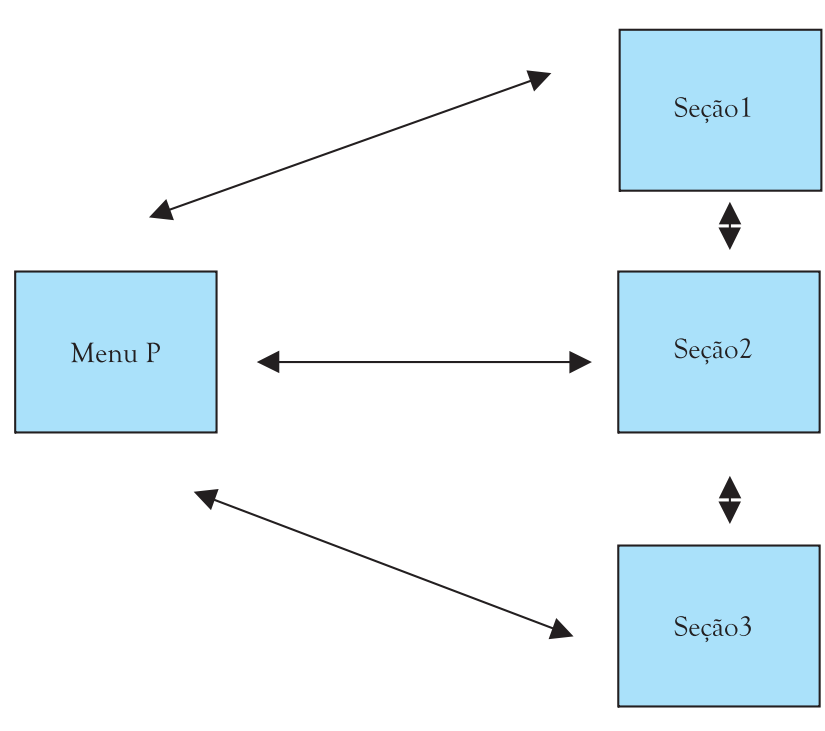

FIGURA 2

Página de entrada (homepage)

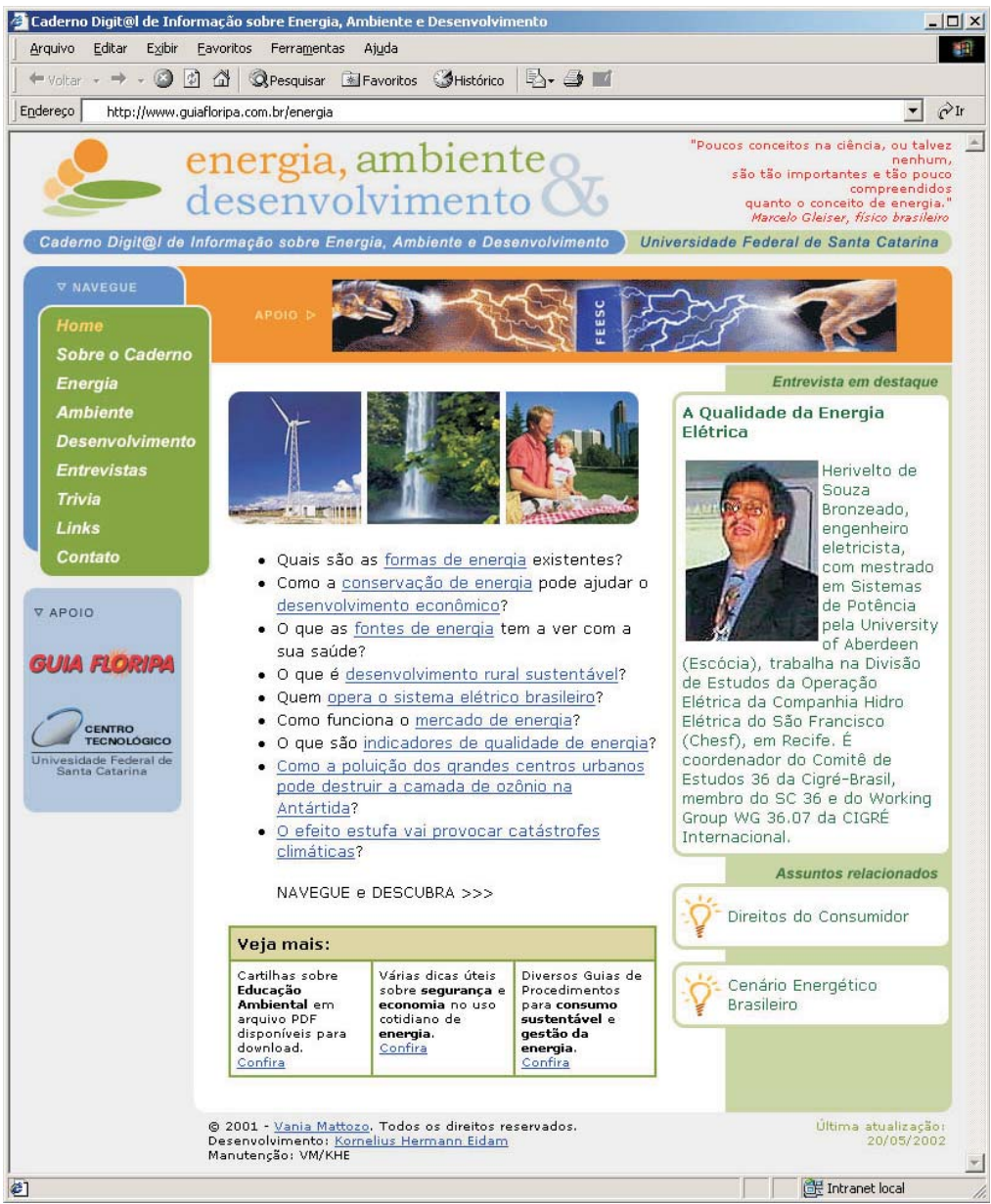




\section{RESULTADOS}

O projeto do Caderno Digital de Informação sobre Energia, Ambiente e Desenvolvimento foi concluído e testado em novembro de 2001. Depois de testado localmente e de serem depuradas algumas falhas na estrutura de navegação e conteúdo, o Caderno foi implementado em rede no final daquele mês. A seguir, realizou-se um trabalho de divulgação, primeiramente entre os profissionais e estudantes que participaram do levantamento de opinião e, a seguir, com os especialistas, pesquisadores e técnicos entrevistados. Com a boa recepção obtida, cadastrou-se o Caderno em alguns dos principais mecanismos de busca existentes no Brasil (Miner, Cadê, Achei, Radar Uol, Biblioteca Virtual de Energia do Conselho Nacional de Desenvolvimento Científico e Tecnológico - CNPq) e no exterior (Yahoo, Altavista e Google). O endereço virtual do Caderno também foi adicionado no portal da Universidade Federal de Santa Catarina, na seção Informações, sob a epígrafe Conservação de Energia.

Como forma de gerenciar o número de acessos e as estatísticas de uso, instalou-se o programa WebTrendsLive (versão freeware), do qual se capturaram as informações registradas nos cinco primeiros meses de funcionamento do site (de dezembro de 2001 a abril de 2002). As estatísticas gerais de acesso e páginas visitadas encontram-se no quadro 1.

\section{QUADRO 1}

Estatística geral dos acessos ao caderno digital

\begin{tabular}{lrrrrr}
\hline Dados considerados & Dez & Jan & Fev & Mar & Abr \\
\hline Total de Acessos às Páginas & 629 & 2.255 & 3.771 & 9.047 & 10.629 \\
Total de Visitas & 186 & 927 & 1.628 & 3.698 & 4.203 \\
Visitas de Retorno & 54 & 170 & 287 & 573 & 729 \\
Total de Usuários no Mês & 136 & 771 & 1.362 & 3.185 & 3.539 \\
\hline \multicolumn{7}{c}{ Média Estatística } \\
\\
\hline Dados Considerados & Dez & Jan & Fev & Mar & Abr \\
Páginas Vistas por Visitante & 4,6 & 2,9 & 2,8 & 2,8 & 3,0 \\
Páginas Vistas por Dia & 23,3 & 72,7 & 134,7 & 291,8 & 354,3 \\
Visitas por Dia & 6,9 & 29,9 & 58,1 & 119,3 & 140,1 \\
\hline
\end{tabular}

\section{CONCLUSÕES}

A experiência confirmou que a apropriação de tecnologias baseadas em aplicativos para Internet resulta em uma alternativa atraente e viável para prover informação sobre ciência e tecnologia. Os resultados obtidos com o Caderno Digital evidenciam o interesse em obter esse tipo de informação e a possibilidade de se manterem informativos virtuais destinados a essa especialidade jornalística. No período analisado (dezembro de 2001 a abril de 2002), o número de visitas cresceu mensalmente $153 \%$ e a média de páginas vistas por dia dobrou nos três primeiros meses, para aumentar em torno de $21 \%$ nos outros meses.

Os dados obtidos também permitem visualizar o interesse no assunto de usuários provenientes de outros países, como Portugal, o segundo país com maior número de visitantes depois do Brasil. Embora com índice menor de acessos, também se registrou um percentual crescente de visitas oriundas de países íbero-americanos, como México e Espanha. Foram recebidas, por meio dos mecanismos de interação, várias mensagens de diversas partes do país (São Paulo, Paraná, Minas Gerais, Rio Grande do Sul, Espírito Santo, Santa Catarina), a maioria com pedidos de informações mais específicas, que receberam encaminhamento de acordo com a solicitação.

Presume-se que a maior contribuição da mídia implementada foi a de apresentar a questão energética contemplada no âmbito do desenvolvimento sustentável, reunindo informações que permitem ao usuário identificar as implicações econômicas, políticas e ambientais relacionados, estabelecendo um novo contexto para o tratamento da informação sobre energia.

\section{Artigo recebido em 23-01-2004 e aceito para publicação em} 24-04-2004.

\section{Agradecimentos}

Os autores agradecem à Fundação de Ensino de Engenharia em Santa Catarina (FEESC), por intermédio da Direção do Centro Tecnológico da UFSC, pelos recursos disponibilizados para implementação do projeto e ao portal Guia Floripa, através de seus diretores, pelo suporte logístico para edição e manutenção do protótipo em rede. 
Jornalismo científico aplicado à área de energia no contexto do desenvolvimento sustentável

\section{REFERÊNCIAS}

1. CORREA, Gilberto Kobler. Energia e fome. São Paulo : Ática, 1987.

2. BARBIERI; José Carlos. Desenvolvimento e meio ambiente: as estratégias de mudanças da Agenda 21. Petrópolis : Vozes, 1997.

3. HERZ, Daniel. Por uma mídia adequada ao respeito dos direitos humanos. Disponível em: 〈http://www.acessocom.com.br/mediaedh.asp>. Acesso em: 2001.

4. ALBAGLI, Sarita. Divulgação científica: informação científica para a cidadania? Revista Ciência da Informação, Brasília, v. 25, n. 3, p. 396 404, set./dez. 1996

5. RABELO, Desirée Cipriano. Comunicación y movilización social en los temas ambientales: a implantación de la Agenda 21 en Brasil. [S. 1.] : Universidad de Salamanca, Disponível em: <http://cts.usal.es/ desiree/Pamplona.rtf>. Acesso em: 2001

6. RAMOS, Luiz Fernando Angerami. Meio ambiente e meios de comunicação. São Paulo : Annablume, 1995.

7. BACCHETTA, Victor. Perfil del periodista ambiental. Diário Sociedad Civil. Disponível em: <http://www.sociedadcivil.cl/nuevodiario/sitio/ informaciones/documento.asp?Id=358>. Acesso em: 2002.

8. BUENO, Wilson da Costa. Os novos desafios do jornalismo científico. Disponivel em: < http://www.jornalismocientifico.com.br/ artigojornacientificowbuenodesafios.htm>. Acesso em: 2001.

9. HERNANDO, Manuel Calvo. Nueva dimensión de una tendência: la comunicación social del conocimiento. Revista Quark. Disponível em: 〈http://www.imim.es/quark/num14/ 014073.htm>. Acesso em: 2001.

10. HEMERY, D.; DEBIER, J. C.; DELÉAGE, J. P. Uma história da energia. Brasília : UnB, 1993.

11.COMISSÃO MUNDIAL SOBRE MEIO AMBIENTE E DESENVOLVIMENTO. Nosso futuro comum. 2. ed. Rio de Janeiro : Fundação Getúlio Vargas, 1991.

12. GOLDEMBERG, José. Energia, meio ambiente $\mathcal{E}$ desenvolvimento. São Paulo : Edusp, 1998.

13. HONTY, Gerardo. Impactos ambientales del sector energético en el
Mercosur. [S. 1.] : CEUTA, [2002?]. Disponível em: <http:// www.icem.org.br/Impactos\%20ambientales.doc>. Acesso em: 2002.

14.COMISSÃO DAS COMUNIDADES EUROPÉIAS. Energia e desenvolvimento: quais desafios? Quais métodos? Síntese e conclusões. Tradução Maria Teresa Indiani de Oliveira. Rio de Janeiro : Marco Zero, 1986.

15. MEDINA, Cremilda. Notícia um produto à vend: jornalismo na sociedade urbana e industrial. 2. ed. São Paulo : Summmus, 1988.

16. CORREA, Juan Alberto. La internet como medio de comunicación social interactivo. Disponível em: <http://members.tripod.com/ nuevoperiodismo/p21/medio1.htm>. Acesso em: 2002.

17.COLLE, Raymond. Del diario electrónico al hiperinformativo del ciberespacio. Disponível em: <http://facom.udp.cl/CEM/TDC/ estudios/hiperin/hiperin.htm>. Acesso em : 2002.

18. SABBATINI, Marcelo. Aplicaciones multimedia y comunidades virtuales en um servicio de información médica on-line: nuevos formatos para la divulgación científica. Disponível em: <http://www.webpraxis.com/ msabba/artigos/cong-pamplona99.htm>. Acesso em: 2000.

19. JURBERG, Cláudia. A construção de um ambiente na internet de educação a distância em jornalismo científico. In: Portal do jornalismo científico. Disponível em:< http://www.jornalismocientifico.com.br/ casesclaudiajurberg.htm>. Acesso em: 2000.

20. MACEDO. Mônica. divulgação científica interativa. Disponível em: 〈http://www.intercom.org.br/papers/xxii-ci/gt11/11m07.PDF>. Acesso em: 2000

21. NIELSEN, Jacob. Alertbox five years retrospective. Disponível em: <http:// www.useit.com/alertbox/20000528.html>. Acesso em: 2001.

22. Top tenmMistakes of web management. Disponível em: <http://www.useit.com/alertbox/9706b.html>. Acesso em: 2001.

23. When bad design becomes the standard. Disponivel em:

<http://www.useit.com/ alertbox/991114.html>. Acesso em: 2001. 